\title{
Talking heads: Morphological variation in the human mandible over the last 500 years in the Netherlands
}

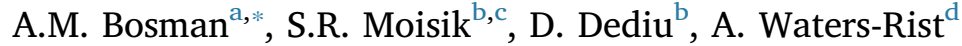 \\ a DFG Centre for Advanced Studies 'Words, Bones, Genes, Tools: Tracking Linguistic, Cultural and Biological Trajectories of the Human Past', \\ University of Tübingen, Rümelinstraße 19-23, D-72070 Tübingen, Germany \\ b Max Planck Institute for Psycholinguistics, Wundtlaan 1, 6525 XD Nijmegen, The Netherlands \\ ${ }^{\mathrm{c}}$ Division of Linguistics and Multilingual Studies, School of Humanities and Social Sciences, Nanyang Technological University, 14 Nanyang Drive, \\ Singapore 637332, Singapore \\ ${ }^{\mathrm{d}}$ Osteoarchaeology and Funerary Archaeology, Faculty of Archaeology, Leiden University, Einsteinweg 2, 2333 CC Leiden, The Netherlands
}

\begin{abstract}
A B S T R A C T
The primary aim of this paper is to assess patterns of morphological variation in the mandible to investigate changes during the last 500 years in the Netherlands. Three-dimensional geometric morphometrics is used on data collected from adults from three populations living in the Netherlands during three time-periods. Two of these samples come from Dutch archaeological sites (Alkmaar, 1484-1574, $n=37$; and Middenbeemster, 1829-1866, $n=51$ ) and were digitized using a 3D laser scanner. The third is a modern sample obtained from MRI scans of 34 modern Dutch individuals.

Differences between mandibles are dominated by size. Significant differences in size are found among samples, with on average, males from Alkmaar having the largest mandibles and females from Middenbeemster having the smallest. The results are possibly linked to a softening of the diet, due to a combination of differences in food types and food processing that occurred between these time-periods. Differences in shape are most noticeable between males from Alkmaar and Middenbeemster. Shape differences between males and females are concentrated in the symphysis and ramus, which is mostly the consequence of sexual dimorphism. The relevance of this research is a better understanding of the anatomical variation of the mandible that can occur over an evolutionarily short time, as well as supporting research that has shown plasticity of the mandibular form related to diet and food processing. This plasticity of form must be taken into account in phylogenetic research and when the mandible is used in sex estimation of skeletons.
\end{abstract}

\section{Introduction}

The mandible is the largest bone in the human face. It holds the lower teeth and provides insertion areas for several muscles. Our interest in the mandible is part of an interdisciplinary project aimed at better understanding the effects of the anatomy and physiology of the vocal tract on patterns of cross-linguistic diversity (Dediu et al., 2017). While language and speech are primarily functions of the brain, previous research has shown that variation in both soft and hard tissue elements of the vocal tract can result in inter-individual differences in language and speech, both pathological (e.g., cleft lip and palate) and as components of normal variation (Brunner et al., 2009; Tiede et al., 2005). The proposal that inter-population differences and variation in the anatomy of the

\footnotetext{
* Corresponding author.

E-mail address: abel.bosman@ifu.uni-tuebingen.de (A.M. Bosman).
} 
vocal tract might shape differences between languages is still debated (Brunner et al., 2009; Dediu, 2011; Dediu and Ladd, 2007; Moisik and Dediu, 2015; Moisik and Dediu, 2017). However, before we can even begin to investigate the possible relationship between genetics, anatomy of the human vocal tract, and linguistic diversity, a better understanding of the anatomical variation in vocal tract structures, of their genetic and environmental causes, and their geographic and temporal patterns is needed.

Anatomical variation of the mandible is also interesting for reasons that have nothing to do with speech and language, such as the morphological differences between females and males which are used for sex estimation. Male mandibles are typically larger and more robust, with squarer chins, and more acute gonial angles whereas female mandibles are typically smaller and more gracile with rounder chins and more obtuse gonial angles (Buikstra and Ubelaker, 1994; Franklin et al., 2007; Hubbe et al., 2009; KemkesGrottenthaler et al., 2002; Schmittbuhl et al., 2001; Steyn and İşcan, 1998). Also, males typically exhibit stronger muscle forces, which can produce rougher surfaces of muscle attachments, increased mass of attachment sites and increased eversion in the gonial angle (Bejdová et al., 2013; Lieberman et al., 2004). However, this 'typical' morphology is by no means completely reliable and has been challenged multiple times. Gonial eversion is one of these debated traits. Even though it has a long history of use in the estimation of sex, Loth and Henneberg (2000) have pointed out that the accuracy of sex-estimation using gonial eversion was quite low. They put forward that gonial eversion is rather a characteristic of facial architecture, linked to the masseter muscle, instead of a sexually dimorphic trait (Loth and Henneberg, 2000). Moreover, an investigation into the accuracy of this trait using geometric morphometrics has shown that while different tendencies exist between the gonial eversion of male and female mandibles, it is not accurate enough to predict the sex of an individual (Oettlé et al., 2009).

Thus, while morphological traits of the mandible have been used to estimate the sex of individuals from skeletons, not all of these traits are reliable indicators on their own, with studies reporting differing accuracies when using these traits to estimate the sex of individuals from different populations (e.g. Loth and Henneberg, 1996; Hu et al., 2006; Franklin et al., 2007; Tuli et al., 2000). Moreover, it has been debated whether using nonmetric traits to estimate the sex of an individual from the mandible is accurate at all. This is highlighted by a study by Maat et al. (1997), who show a low accuracy of sex estimation on female mandibles in the Low Countries. Moreover, research has shown that the shape of the mandible reflects population history and phylogenetic background to a considerable extent (Bejdová et al., 2013; Godde, 2015; Martin and Danforth, 2009). Additionally, a recent study by Alarcón et al. (2016) has shown differences in the pattern of sexual dimorphism between meso-, dolicho-, and brachyfacial mandibles. Thus, mandibular form is influenced by a combination of factors such as transforming demographic structures, changing mortality patterns, improved dental and medical care, changes in diet and processing of food, and interaction with overall facial shape. These factors might confound the usefulness of the mandible in the estimation of sex. On the other hand, some authors, like Thayer and Dobson (2010), argue that some traits, like the mentum osseum, are foremost influenced by sexual dimorphism and thus might overshadow morphology caused by other factors.

Over the years, it has been suggested that diet is an important factor in size and shape differences of the mandible (von CramonTaubadel, 2011; Weisensee and Jantz, 2011). If foods are more highly processed and hence softer, chewing forces are eased, causing less stress on certain areas of the jaw and producing more gracile mandibles. This hypothesis, while not directly supported by experimental evidence in humans, is widely attested (Bejdová et al., 2013; Lieberman et al., 2004; Little et al., 2006). For example, Martin and Danforth (2009) pointed out that the average bicondylar breadth has decreased over time. They relate this process to muscle attachment activity associated with diet. As foods become softer, the strain on the mandibular muscles lessens. In turn, the strain of the mandibular muscles on the ramus decreases and the bone undergoes less remodelling and growth to accommodate these strains. Rando et al. (2014) linked this same process to the softening of diet during the Industrial Revolution, when people had more access to goods such as sugar and finely milled flour.

During the late Medieval period (15th and 16th centuries), people probably ate a combination of grains, such as, wheat, rye, oats, and barley. This was supplemented by beans and lentils, fish, and, on rare occasions, meat (Reitsema and Vercellotti, 2012; Singman, 1999). In the 18th and 19th centuries, the potato was added to this diet (Wiel, 2012). The potato is a very soft food when cooked and could have been a primary factor in the reduction of masticatory stress in the 18th and 19th centuries (Paschetta et al., 2010; Vanhaute et al., 2007). Also, the economy of the one of the areas researched in this study was centred upon cattle farming, so soft dairy products could have been a substantial part of their regular diet (Wiel, 2012). Furthermore, the start of the Industrial Revolution meant that food became more processed due to technological improvements. There is some evidence that this processing was happening on a general level (Vanhaute et al., 2007), although, it is not known to what extent this processing led to a softer diet in the post-Medieval period in the Netherlands. Moreover, we currently do not have data on shape changes in the mandible during this period.

Diet and sexual dimorphism are not necessarily two unrelated factors, since it could be the case that, if living standards improve, sexual dimorphism is expressed more clearly. This is related to life history theory, which assumes that energy is a scarce resource that must be spread over different functions such as body maintenance, the immune system, growth, and reproduction (Hill and Kaplan, 1999). If energy availability decreases or is already low during birth and periods of skeletal maturation, less energy can be devoted to growth and sexual dimorphism since more is needed for survival. Furthermore, if a population-wide general stress is assumed, males and females are not equally affected by this stress. During puberty, which is a period in which humans experience fast skeletal growth, boys and girls experience different kinds of bone growth. Due to greater periosteal and endocortical expansion before puberty in boys, boys have a greater mass of cortical bone than girls (Seeman, 2001). Delayed puberty, which can be a result of nutritional stress (Magner et al., 1984), leaves boys with smaller bones with a thinner cortex but a normal medullary diameter. Girls will have normal bones with thinner cortex and a larger medullary diameter (Hill and Kaplan, 1999). These changes in general bone size could hypothetically cause a decrease in sexual dimorphism, as skeletal remains belonging to male individuals should appear to be smaller and more comparable with females. However, it should be noted that a large-scale study on the effect of delayed puberty on sexual 
dimorphism of the skeletal structure in humans has not yet been performed. Also, Quintelier et al. (2014) demonstrated, based on isotopic evidence, that males from post-Medieval Belgium (16th-18th century) probably had a higher intake of animal protein (meat and fish). A difference in meat consumption could potentially contribute to the differences in the shape and size (or just one of these) of male versus female mandibles, since the differences in structure between foods, or even between processed and un-processed foods, can have an impact on the muscle activity needed for chewing (Zink and Lieberman, 2016).

As previous sections have pointed out, multiple factors have been put forward that might be responsible for diachronic shape changes in the mandible. In this study, we use three-dimensional (3D) geometric morphometrics to analyze size and shape variation independently but also their interaction, and possible correlations with other factors (Zelditch et al., 2012). With this method, our primary aim is to explore the extent of the morphological variation of the human mandible in the Netherlands, by comparing three samples from different time periods, and to investigate changes in mandibular morphology over the last 500 years and their possible causes. A secondary aim is to closely analyze the amount and pattern of sexual dimorphism in these samples in order to identify the factors involved in the purportedly more masculine morphology of female mandibles in the Netherlands during the post-Medieval period.

\section{Materials}

\section{Samples}

The oldest of the archaeological sites, Alkmaar, is a part of a monastic cemetery, which was in use between 1484 and $1574 \mathrm{CE}$ (Griffioen et al., 2015). The more recent site, Middenbeemster, is a Protestant Church cemetery, with mandibles dating to 1829 until 1866 CE (Lemmers et al., 2013). The ArtiVarK sample consists of 34 contemporaneous Dutch individuals and is based on data collected with a MRI scanner. In the following analyses, sample refers to the different time-periods (Alkmaar, Middenbeemster and ArtiVarK), while sex refers to either males or females. Furthermore, the term 'groups' refers to the combination of sample and sex.

Selection of the sample was based, primarily, on estimated sex and age-at-death (Table 1). The individuals were also classified according to two age categories, namely Young Adults (18-35 years of age) and Middle Adults (35-60 years of age). Only adults were used in this study in order to suppress the effect of ontogenetic allometry. If children (individuals under 18 years) would be included in the sample, a large amount of shape change could be significantly influenced by growth. While the age range of adults in archaeological samples is still quite large (18-60 years), growth during this age period is limited when compared to the age categories preceding the adult stage. Estimation of age at death was achieved by combining the results of several different methods: sternal rib end deformation developed by İşcan et al. (1984), cranial suture closure developed by Meindl and Lovejoy (1985), pubic symphysis changes developed by Brooks and Suchey (1990), dental attrition ageing published by Maat (2001), and finally the auricular surface ageing method developed by Buckberry and Chamberlain (2002). Estimation of sex was done according to the standards by Buikstra and Ubelaker (1994). These standards were supported by the methods concerning the sexing of the pubic bone, published by Phenice (1969). When the selection of individuals was done, only individuals for which the most probable sex could be established through traits of the pelvis, cranium, and post-cranial measurements were selected. This was done in order to avoid the inherent bias that could arise by including individuals with a sex estimation based only on the mandible as their mandibular traits would be distinctly male/female.

\section{Methods}

A NextEngine 3D surface laser scanner was used by one of the authors $(A B)$ to create virtual models of mandibles from the Alkmaar and Middenbeemster collections, which were subsequently refined with MeshLab (source: http://meshlab.sourceforge.net/). Twenty-seven fixed landmarks and nine curves consisting of semilandmarks were placed on the models using Landmark Editor (Wiley et al., 2005). Three of the fixed landmarks were situated on the midsagittal plane; the others consisted of twelve pairs of points on the left and right sides of the mandible. Likewise, one of the semilandmark curves was located on the midsagittal plane while the other curves were bilaterally homologous.

The modern data were collected as part of the ArtiVarK study (Dediu and Moisik, 2016). The data were collected with a $1.5 \mathrm{~T}$ magnetic resonance imaging (MRI) system (Avanto, Siemens Healthcare) at the Donders Institute for Brain, Cognition and Behaviour (in the Donders Centre for Cognitive Neuroimaging, Nijmegen, The Netherlands). The participants were healthy individuals, 18 females and 16 males, screened for history of major orthodontic disease or interventions and/or orofacial surgery; the mean age was 27.6 years (ranging from 18 to 61 years). Participants were fitted with a six-channel head and neck RF receiver coil array to enhance

Table 1

The division of the sexes, samples and age groups used in this study.

\begin{tabular}{llllr}
\hline Samples & Males & Females & Young adults & Middle adults \\
\hline Alkmaar (PAA) & 14 & 23 & 20 & 17 \\
Middenbeemster (MB) & 28 & 23 & 31 & 20 \\
ArtiVarK (AAR) & 16 & 18 & 27 & 7 \\
Total & 58 & 64 & 78 & 44 \\
\hline
\end{tabular}


Table 2

Definitions of the landmarks used in this study. The first 12 landmarks are bilateral, while the last three landmarks are located midline.

\begin{tabular}{|c|c|c|}
\hline Number & Landmark & Location \\
\hline 1 and 16 & Coronion $(\mathrm{C})$ & Most superior point of the coronoid process \\
\hline 2 and 17 & Mandibular notch (Mn) & Most inferior point on the mandibular notch. Also known as the c-point \\
\hline 3 and 18 & Condyle tip (Ct) & Most superior point on mandibular condyle \\
\hline 4 and 19 & Condylion mediale $(\mathrm{Cm})$ & Most medial point on mandibular condyle \\
\hline 5 and 20 & Condylion laterale $(\mathrm{Cl})$ & Most lateral point on mandibular condyle \\
\hline 6 and 21 & Root of Sigmoid process (Sp) & Point where the mandibular notch intersects the condyle \\
\hline 7 and 22 & Posterior ramus (Pr) & Point at which the minimum breadth transects the posterior border of the ramus \\
\hline 8 and 23 & Gonion (G) & $\begin{array}{l}\text { The most lateral external point of junction of the horizontal and ascending rami of the lower jaw. Constructed } \\
\text { using line tangents drawn from the vertical horizontal ramus and the inferior margin }\end{array}$ \\
\hline 9 and 24 & Anterior ramus (Ar) & Point at which the minimum breadth transects the anterior border of the ramus \\
\hline 10 and 25 & Posterior alveolar $(\mathrm{Pa})$ & Most posterior point on labial alveolar surface behind most posterior erupted tooth \\
\hline 11 and 26 & Mental foramen (F) & Point in the middle of the mental foramen \\
\hline 12 and 27 & Canine (Ca) & Point on alveolar margin between canine and first premolar \\
\hline 13 & Gnathion (Gn) & Most inferior midline point on symphysis \\
\hline 14 & Pogonion (Po) & Most projecting point of the chin in standard sagittal line \\
\hline 15 & Infradentale (I) & Midline point at superior tip of septum between mandibular central incisors \\
\hline
\end{tabular}

the signal in the region of the vocal tract. Three-dimensional structural scans were obtained using a T1-weighted sequence (MPR NS PH8, TE $=2.98 \mathrm{~ms}, 98 \mathrm{TR}=2250 \mathrm{~ms}$, flip angle $15^{\circ}$, slice thickness $1 \mathrm{~mm}$, pixel spacing $1 \mathrm{~mm} \times 1 \mathrm{~mm}$, FOV $256 \times 99256$ )

The landmark data from the ArtiVarK study only consist of the pogonion, gnathion, gonion and condylion landmarks, since this study was performed without the initial intention of correspondence with the Alkmaar and Middenbeemster datasets. These samples were landmarked using a custom user interface developed in Matlab (Mathworks Inc.) for landmarking MRI data by one of the authors (SRM). In the statistical analyses, when compared with the ArtiVarK sample, the datasets from Alkmaar and Middenbeemster were reduced to these landmarks to facilitate proper comparison.

The landmarks and semilandmarks (Tables 2 and 3) were defined according to conventions described in multiple publications (Bookstein, 1991; Franklin et al., 2007; Nicholson and Harvati, 2006). Concerning the sliding semilandmarks algorithm, it was decided that the minimum Procrustes distance criterion should be used. With this criterion, the differences in semilandmark positions along the curve between the reference form and each specimen are removed by estimating the direction tangential to the curve and removing the component of the differences along this tangent (Perez et al., 2006).

The landmark and semilandmarks coordinates were superimposed using a partial generalized Procrustes analysis (GPA). GPA superimposes landmark configurations by translating them to a common origin. Subsequently, the landmark configurations were scaled to unit centroid sizes and were rotated until the coordinates of corresponding points aligned as closely as possible. This procedure removes size, translation and rotation as factors, while size-related shape changes are maintained (Zelditch et al., 2012). To facilitate the visualization and interpretation of data, principal component analysis (PCA) and between group principal component analysis (bgPCA) were used.

In order to determine the effect of size on the morphological variation of the mandible, several tests of allometry were performed. Differences in centroid sizes were compared between samples and sexes with an ANOVA and a post hoc pairwise $t$-test with pooled SD in order to determine differences in size between the groups. Moreover, a Procrustes ANOVA was performed to quantify the relative amount of shape variation attributable to covariation with organism size in a linear model. The ANOVA uses sequential (Type I) sums of squares. Also, the Procrustes ANOVA used here calculates the common allometric component of the shape data, which is an estimate of the average allometric trend within groups (Mitteroecker et al., 2004). This is then used for plotting the results in order to check homogeneity of allometric slopes.

All Procrustes ANOVA analyses were performed with 10,000 permutations and randomized residual permutation procedure (RRPP), which is a probability distribution generation method that resamples linear model residuals (Collyer et al., 2015). Finally, since stature (as an aspect of body size) could possibly influence mandibular size, it was necessary to investigate the correlation between those two variables. Stature was estimated from long bone length by the method of Trotter (1970). The stature of five individuals from Alkmaar could not be estimated due to incompleteness of the long bones. An ANOVA and post hoc Student's $t$-tests

Table 3

The semi-landmarks used in this study. First semi-landmark curve is not bilateral; other curves are bilateral. 'Count' denotes the number of semi-landmarks which establish the curve.

\begin{tabular}{|c|c|c|c|}
\hline Number & Curve name & Definition & Count \\
\hline 1 & Symphysis (Sy) & Curve on the sagittal midline over the symphysis, starts at infradentale, ends at gnathion & 6 \\
\hline 2 and 6 & Lower mandible (Lm) & Lower mandibular border, starts at gnathion, ends at gonion & 32 (16 on each side) \\
\hline 3 and 7 & Posterior ramus (Pr) & Posterior part of the ascending ramus, starts at the gonion, ends at the posterior condyle & 24 (12 on each side) \\
\hline 4 and 8 & Sigmoid notch (Sn) & Curve of the mandibular notch, starts at the sigmoid process, ends at the coronoid process & 12 ( 6 on each side) \\
\hline \multirow[t]{3}{*}{5 and 9} & Anterior ramus (Ar) & Anterior ridge of the ascending ramus, starts at coronoid tip, ends at anterior ramus & 12 ( 6 on each side) \\
\hline & & Total semilandmarks on curves & 86 \\
\hline & & Total amount of coordinates (landmarks and semilandmarks) & 113 \\
\hline
\end{tabular}


Table 4

PCA summaries of Alkmaar and Middenbeemster and the total sample. The rest of the PC's (17-88 for the total) explain less than 5\% of variation and are not detailed.

\begin{tabular}{|c|c|c|c|c|c|}
\hline PC PAA ${ }^{*}$ and $\mathrm{MB}^{* * *}$ & $\%$ variance & Cumulative percentage & PC total & $\%$ variance & Cumulative percentage \\
\hline 1 & 24.2 & 24.2 & 1 & 36.0 & 36.0 \\
\hline 2 & 18.2 & 42.4 & 2 & 23.8 & 59.8 \\
\hline 3 & 8.2 & 50.6 & 3 & 14.8 & 74.6 \\
\hline 4 & 6.6 & 57.2 & 4 & 11.7 & 86.4 \\
\hline 5 & 4.6 & 61.8 & 5 & 5.1 & 91.4 \\
\hline
\end{tabular}

$*$ PAA $=$ Alkmaar.

** MB $=$ Middenbeemster.

were performed on the remaining individuals to check for the differences in mean stature for the three sites. A Welch's $t$-test was performed to check for the differences in mean stature for the two sexes. A Procrustes ANCOVA was used to test the interaction between the shape, size of the mandible and stature.

In the analyses outlined above, the significance level was set at 0.05 . Equality of variance was achieved unless noted otherwise. All statistical analyses were performed with the geomorph package (Adams and Otarola-Castillo, 2013) in R (R Development Core Team, 2008). Furthermore, figures were created with geomorph and ggplot2 (Wickham, 2009). To assess intra-observer error, ten models were selected randomly which had no post-mortem damage on landmark locations. This was done to limit the effect of induced generalization caused by reconstruction. Landmarks were placed on these models following the procedure outlined above. This was done again a week later, under the same conditions. Subsequently, the mean deviation was calculated per landmark. The mean deviation was $0.062 \mathrm{~mm}$.

\section{Results}

The first principal component explained $24.2 \%$ of the variation in the archaeological samples, while the second component explained $18.2 \%$ of the variation (Table 4; Fig. 1). If all the components explaining more than $1 \%$ of the data were included, principal

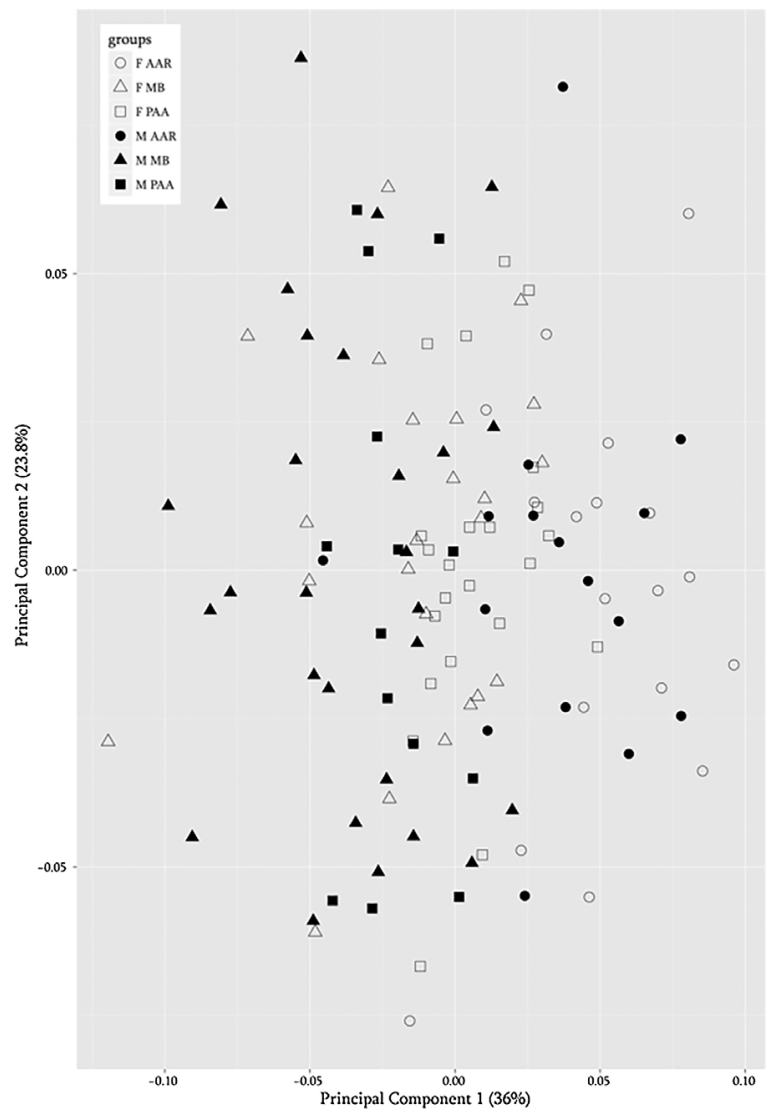

Fig. 1. PC1 versus PC2 of the total sample. Triangles represent males and circles represent females. Abbreviations: AAR $=$ ArtiVarK, MB $=$ Middenbeemster, PAA = Alkmaar. 

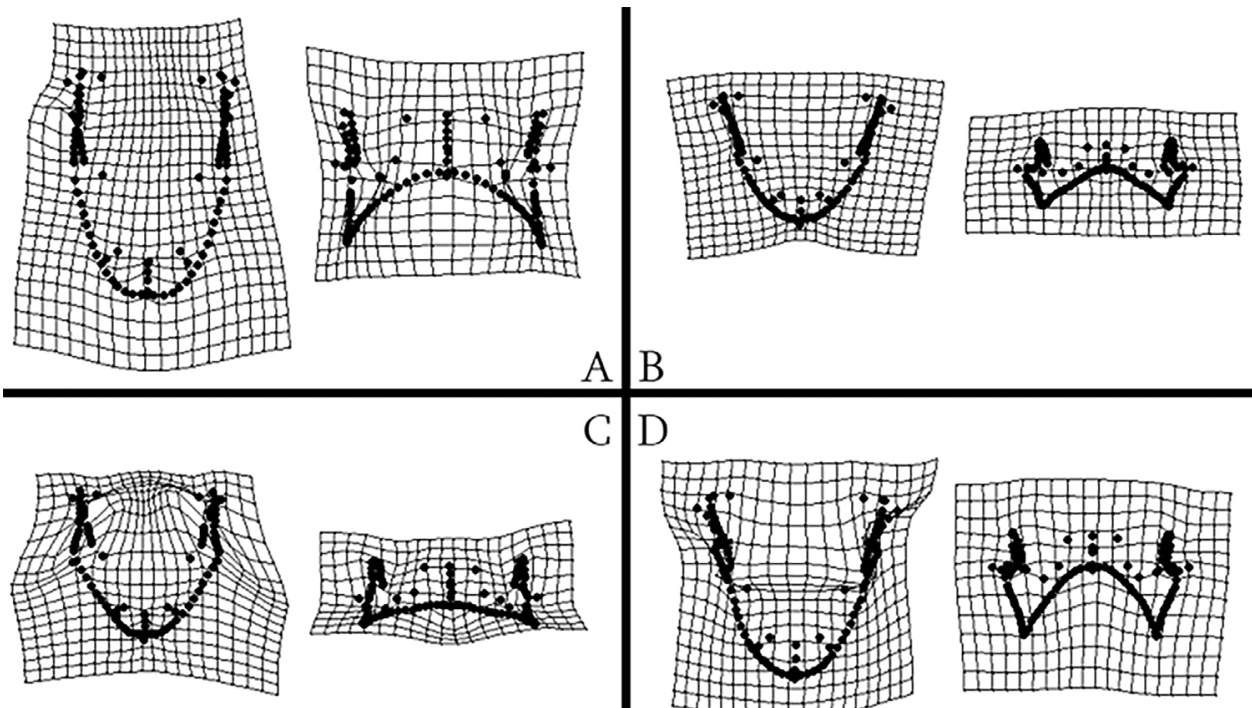

A B

C D
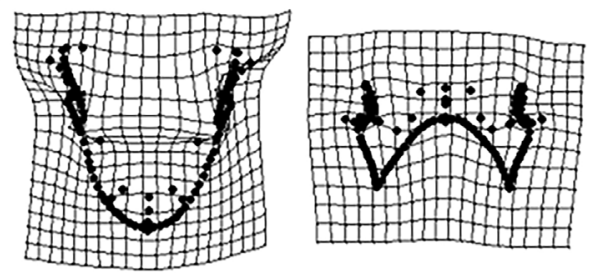

Fig. 2. Thin plate splines associated with the two PC's of the total sample. Each row represents a different PC. The left warps of each pair are viewed from the inferior of the mandible, with the mandibular symphysis facing the inferior. The right warps of each pair are from the anterior aspect, with the mandibular symphysis facing the viewer. (A) Minimum of PC1; (B) maximum of PC1; (C) minimum of PC2; (D) maximum of PC2.

components 1-16 explain $84.2 \%$ of the variation. When considering the total sample (including ArtiVarK), the first principal component explained $36 \%$ of the variation, while the second principal component explained $23.8 \%$ of total variation. The first two PC scores of the Middenbeemster and Alkmaar comparison are represented by TPS warps (Fig. 2). The minimum of PC1 reflects anterior projection of the symphysis and medial flexure of the mandibular rami, while the maximum on this axis reflects antero-posteriorly short and medio-laterally wide mandibles. PC2 represents the tilt of the mandibular symphysis, antero-posterior flexure of the ramus and eversion of the gonions and the flexure in the inferior portions of the rami. The minimum of PC2 shows an inferiorly tilted symphysis, posteriorly flexing rami and everted gonial angles. The maximum of PC2 shows a superiorly tilted symphysis, anteriorly flexing rami and inverted gonial angles.

The bgPCA results (Fig. 3) show that individuals are spread in many directions around their respective means and show considerable overlap with other groups. Therefore, the overall classification accuracy is poor (55.68\%). However, if a bgPCA is performed while only separating the sexes and pooling the sites, the overall classification goes up to $75 \%$.

\section{Multivariate statistics}

First, an unpaired Student's $t$-test was performed to compare the young adult and middle adult age categories and the result was not significant $(t=-0.78513 \mathrm{df}=104, P=0.41$ ). This justifies not separating the groups by age. A one-way-ANOVA found size differences between the sites and the sexes $(F$-value $=50.213, P<2.2 \mathrm{e}-16)$. Subsequently, a post hoc pairwise $t$-test was performed in order to check for specific differences between the sexes and the sites. These pairwise tests were all significant (Fig. 4).

A second pairwise $t$-test was performed on the set including the ArtiVarK sample. This test found significant differences between most of the groups, except between males from ArtiVarK and Alkmaar, males and females from ArtiVarK and Middenbeemster, and females from ArtiVarK and Alkmaar.

The Procrustes ANOVA with size as a covariate found a significant association between centroid size and shape $(F=2.533$, $\left.Z=2.51, R^{2}=0.028611, P=0.01\right)$. A subsequent non-parametric MANOVA test was performed to check for the interaction between the sample and the categorical factors of sex and sample, while accounting for the influence of size. Sex had a significant association with shape change in the Procrustes residuals $\left(F=4.9333, Z=4.0750, R^{2}=0.050775, P=0.0001\right)$. Also, the differences among samples had a significant influence $\left(F=4.0506, Z=6.4855, R^{2}=0.076785, P=0.0001\right)$. However, the interaction between sex and sample was not significant $\left(F=0.7656, Z=0.7309, R^{2}=0.007880, P=0.66\right.$ ). The pairwise distances between the slope vectors and slope correlation indicate that, in some cases, there was a difference in shape when size was not accounted for. The landmarks on the mandibles from Alkmaar and Middenbeemster were then separated into the corpus and rami specifically, in order to pinpoint more local effects (Tables 5 and 6).

For some pairwise combinations, there was a different direction of size-associated shape change. This was significant for: (1) the males and females from Middenbeemster concerning the total configuration and the corpus; (2) the males and females from Alkmaar concerning the total configuration and the rami separately, and; (3) the males from Alkmaar and Middenbeemster concerning the total configuration and the corpus. Subsequently, the same approach was repeated while including the ArtiVarK sample.

The interaction between stature and shape of the mandible was investigated by using four tests. An ANOVA with a post hoc pairwise Student's $t$-test was performed to check for differences in stature between the three sites. These tests have pointed out that 


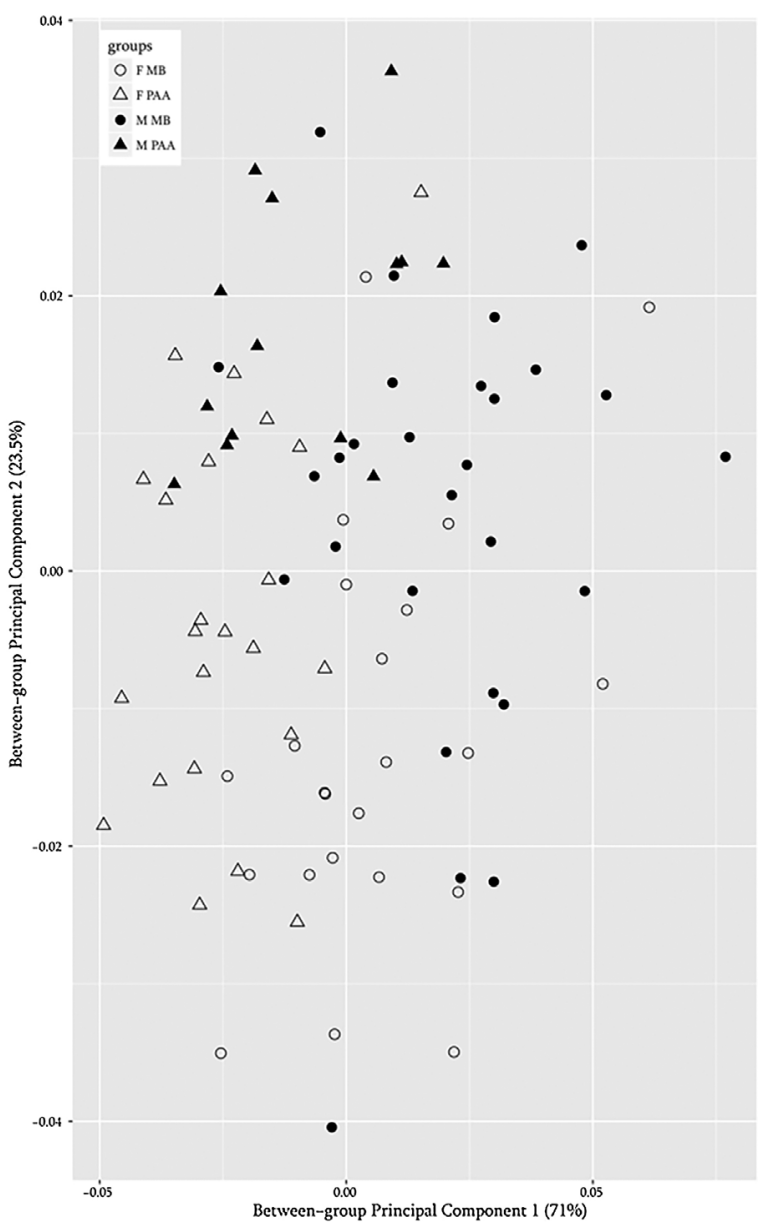

Fig. 3. Between group PCA of the archaeological samples. $M$ MB = males from Middenbeemster, $M$ PAA = males from Alkmaar, $F$ MB = females from Middenbeemster, F PAA = females from Alkmaar.
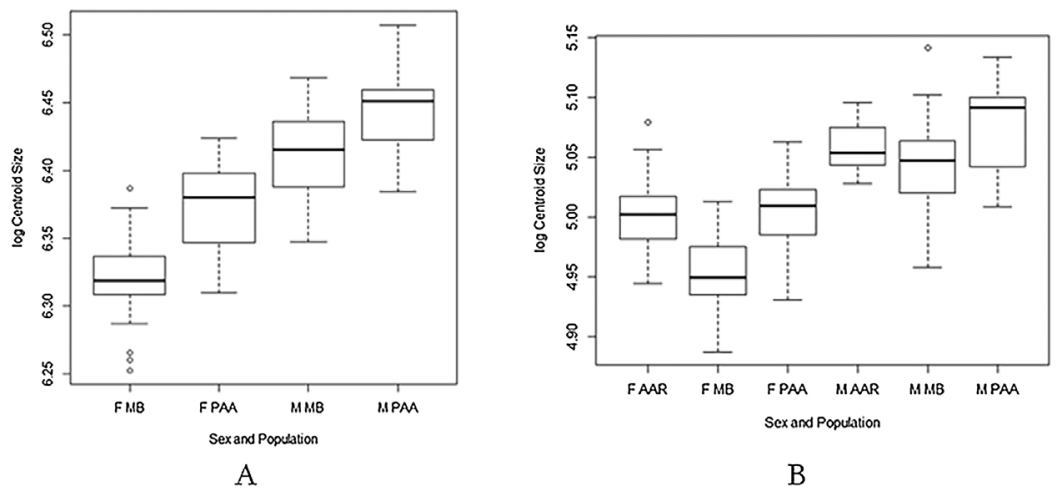

Fig. 4. Box-and-whisker plots of the logarithms of the centroid sizes extracted from the landmark subsets. Abbreviations: MB = Middenbeemster, PAA = Alkmaar, AAR = ArtiVarK. Letters F and M indicate females and males respectively. The black bar denotes the median, while the upper and lower limits of the box represent the upper and lower quartile, respectively. The upper and lower whiskers represent the greatest and least values (excluding outliers), respectively. The open circles portray the outliers. (A) Centroid sizes from Alkmaar and Middenbeemster, (B) centroid sizes from the complete sample, based on only the landmarks.

there are significant differences in stature between Middenbeemster and ArtiVarK $(P=0.0000026)$, as well as between Alkmaar and ArtiVarK $(P=0.00052)$. There were no significant stature differences between Alkmaar and Middenbeemster $(P=0.74)$. A Welch's $t$-test, performed to check for stature differences between the two sexes was significant $(t=3.8957, \mathrm{df}=72.735, P=0.0002)$. A Procrustes ANCOVA showed that stature is not statistically significant for shape $\left(F=1.2909, Z=1.0758, R^{2}=0.011101\right.$, $P=0.25)$. However, the interaction between stature and centroid-size was significant $(F=80.06, P<0.000001)$. Table 7 details 
Table 5

Pairwise distance between slope vectors which represent the difference in the magnitude of shape change (Alkmaar and Middenbeemster). Values above diagonal are $P$-values, values below diagonal are average Procrustes distances per unit of covariate change.

\begin{tabular}{|c|c|c|c|c|}
\hline Total & MB F & MB M & PAA F & PAA M \\
\hline MB F & & $0.04^{*}$ & 0.75 & 0.96 \\
\hline MB M & 0.626991 & & 0.19 & 0.10 \\
\hline PAA F & 0.391042 & 0.513074 & & 0.58 \\
\hline PAA M & 0.381786 & 0.652553 & 0.492204 & \\
\hline Corpus & MB F & MB M & PAA F & PAA M \\
\hline MB: F & & $0.01^{*}$ & 0.62 & 0.86 \\
\hline MB: M & 0.404022 & & 0.1 & $0.04^{*}$ \\
\hline PAA: F & 0.227742 & 0.319653 & & 0.53 \\
\hline PAA: M & 0.225540 & 0.417754 & 0.278048 & \\
\hline Rami & $\mathrm{MB} F$ & MB M & PAA F & PAA M \\
\hline MB F & & 0.08 & 0.76 & 0.95 \\
\hline MB M & 0.479462 & & 0.29 & 0.12 \\
\hline PAA F & 0.317880 & 0.401331 & & 0.58 \\
\hline PAA M & 0.308046 & 0.501305 & 0.406145 & \\
\hline
\end{tabular}

* $P<0.05$

$* * P<0.01$

*** $P<0.001$.

$\mathrm{MB}=$ Middenbeemster, PAA $=$ Alkmaar; F - females; $\mathrm{M}-$ males.

Table 6

Pairwise vector correlations between slope angles and $P$-values for pairwise angles between slope vectors (Alkmaar and Middenbeemster). Values above the diagonal are $P$-values, values below are angles represented by vector correlations. High correlation is less significant.

\begin{tabular}{|c|c|c|c|c|}
\hline Total & MB F & MB M & PAA F & PAA M \\
\hline MB F & & 0.04 & 0.45 & 0.75 \\
\hline MB M & -0.241317 & & 0.32 & $0.02^{*}$ \\
\hline PAA F & 0.173483 & 0.095259 & & $0.03^{*}$ \\
\hline PAA M & 0.326439 & -0.352320 & -0.323165 & \\
\hline Corpus & MB F & MB M & PAA F & PAA M \\
\hline MB F & & $0.03^{*}$ & 0.43 & 0.82 \\
\hline MB M & -0.339028 & & 0.20 & $0.02^{*}$ \\
\hline PAA F & 0.171987 & -0.020515 & & 0.1 \\
\hline PAA M & 0.423331 & -0.389667 & -0.202808 & \\
\hline Rami & MB F & MB M & PAA F & PAA M \\
\hline MB F & & 0.08 & 0.46 & 0.63 \\
\hline MB M & -0.179659 & & 0.41 & $0.03^{*}$ \\
\hline PAA F & 0.176873 & 0.150120 & & $0.02^{*}$ \\
\hline PAA M & 0.260192 & -0.327513 & -0.391728 & \\
\hline
\end{tabular}

$* P<0.05$

$\mathrm{MB}=$ Middenbeemster, PAA $=$ Alkmaar; $\mathrm{F}-$ females, $\mathrm{M}-$ males.

the pairwise Student's $t$-test results on the archaeological sites outlined in the main paper while Table 8 details the same test performed on the complete sample. They show that most pairwise differences are significant (Table 7), except between males from ArtiVarK and Middenbeemster, males from ArtiVarK and Alkmaar and females from ArtiVarK and Alkmaar (Table 8). Moreover, pairwise distances and correlations between vectors of shape change when the ArtiVarK sample is included in the total analysis are detailed in Tables 9 and 10. These show that the significant differences between individuals from Middenbeemster and Alkmaar detailed earlier disappear (Tables 9 and 10). This reinforces the notion that the use of only the pogonion, gnathion, gonion and condylion landmarks is insufficient to capture important areas of shape change. 
Table 7

Post hoc pairwise Student's $t$ tests of the centroid sizes with pooled standard deviation. The centroid sizes of Alkmaar and Middenbeemster are considered here. $P$ values have been adjusted with Holm-Bonferroni method.

\begin{tabular}{|c|c|c|c|c|}
\hline & MB male & MB female & PAA male & PAA female \\
\hline MB male & - & $1.3 e-14^{\text {knk }}$ & $0.03^{*}$ & $0.0001^{* k x}$ \\
\hline MB female & $1.3 e-14^{* * * *}$ & - & $<2 \mathrm{e}-16^{* * * k}$ & $2.0 \mathrm{e}-05^{* k * k}$ \\
\hline PAA male & $0.031^{*}$ & $<2 \mathrm{e}-16^{* \ldots *}$ & - & $3.1 \mathrm{e}-08^{* \ldots * k}$ \\
\hline PAA female & $0.00013^{* * * *}$ & $2.0 \mathrm{e}-05^{\text {k*k* }}$ & $3.1 \mathrm{e}-08^{* 3 x}$ & - \\
\hline
\end{tabular}

$* P<0.05$

$* * P<0.01$.

$* * * P<0.001$.

$\mathrm{MB}=$ Middenbeemster, PAA $=$ Alkmaar; $\mathrm{F}-$ females, $\mathrm{M}-$ males.

Table 8

Post hoc pairwise $t$ tests of the centroid sizes with pooled standard deviation. The ArtiVarK study is included here. P-values have been adjusted with Holm-Bonferroni method.

\begin{tabular}{|c|c|c|c|c|c|c|}
\hline & AAR male & MB male & PAA male & AAR female & MB female & PAA female \\
\hline AAR male & - & 0.34 & 0.34 & $2.7 \mathrm{e}-05^{\text {(2) }}$ & 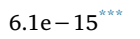 & $2.0 \mathrm{e}-05^{\text {(x) }}$ \\
\hline MB male & 0.34 & - & $0.009^{k * *}$ & $0.00038^{* *}$ & $9.3 e-15^{k \text { knth }}$ & $0.0003^{k * k}$ \\
\hline PAA male & 0.34 & $0.009^{* k *}$ & - & $4.5 e-08^{k * k}$ & $<2 \mathrm{e}-16^{* 2 k \mathrm{ke}}$ & $2.1 \mathrm{e}-08^{\text {*⿻一丿火巾 }}$ \\
\hline AAR female & $2.7 \mathrm{e}-05^{* \star * *}$ & $0.00038^{* * k}$ & $4.5 e-08^{* \ldots * k}$ & - & $0.0002^{* k}$ & 0.87 \\
\hline MB female & $6.1 \mathrm{e}-15^{\text {k站 }}$ & $9.3 e-15^{* k+k}$ & 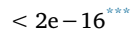 & 0.0002 & - & 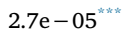 \\
\hline PAA female & $2.0 \mathrm{e}-05^{\mathrm{k} * k}$ & $0.0003^{k * k}$ & $2.1 e-08^{* x *}$ & 0.87 & $2.7 \mathrm{e}-05^{\text {tekne }}$ & - \\
\hline
\end{tabular}

$* P<0.05$.

$* * P<0.01$.

$* * * P<0.001$.

$\mathrm{MB}=$ Middenbeemster, $\mathrm{PAA}=$ Alkmaar, $\mathrm{AAR}=$ ArtiVarK

Table 9

Pairwise distance between slope vectors with the ArtiVarK sample included. Values above diagonal are $P$-values, values below diagonal are average Procrustes distances per unit of covariate change.

\begin{tabular}{|c|c|c|c|c|c|c|}
\hline & F AAR & M AAR & F MB & M MB & F PAA & M PAA \\
\hline F AAR & & 0.567 & 0.899 & 0.613 & 0.803 & 0.954 \\
\hline M AAR & 0.761 & & 0.288 & 0.651 & 0.439 & 0.504 \\
\hline F MB & 0.333 & 0.919 & & 0.107 & 0.838 & 0.730 \\
\hline M MB & 0.437 & 0.673 & 0.622 & & 0.318 & 0.351 \\
\hline F PAA & 0.399 & 0.832 & 0.359 & 0.534 & & 0.378 \\
\hline M PAA & 0.321 & 0.815 & 0.441 & 0.566 & 0.608 & \\
\hline
\end{tabular}

$* P<0.05$

$\mathrm{MB}=$ Middenbeemster, PAA $=$ Alkmaar, AAR $=$ ArtiVarK; $\mathrm{F}-$ females, $\mathrm{M}-$ males.

Table 10

Pairwise vector correlations between slope angles with the ArtiVarK sample included. Values above diagonal are $P$-values, values below are angles represented by vector correlations. High correlation is less significant.

\begin{tabular}{|c|c|c|c|c|c|c|}
\hline & F AAR & M AAR & F MB & M MB & F PAA & M PAA \\
\hline F AAR & & 0.842 & 0.089 & 0.595 & 0.105 & 0.861 \\
\hline M AAR & 0.531 & & 0.236 & 0.877 & 0.583 & 0.660 \\
\hline F MB & -0.467 & -0.260 & & $0.028^{*}$ & 0.420 & 0.404 \\
\hline M MB & 0.313 & 0.594 & -0.604 & & 0.392 & 0.443 \\
\hline F PAA & -0.440 & 0.193 & 0.081 & 0.057 & & 0.063 \\
\hline M PAA & 0.590 & 0.28 & 0.041 & 0.118 & -0.553 & \\
\hline
\end{tabular}

$* P<0.05$

$\mathrm{MB}=$ Middenbeemster, PAA $=$ Alkmaar, AAR $=$ ArtiVarK; $\mathrm{F}-$ females, $\mathrm{M}-$ males.

\section{Discussion}

Regarding the PCA, a large number of principal components were still required to explain most of the variance. Moreover, the first 16 principal components provide poor representation of morphological variation each, which makes their variation difficult to interpret. Likewise, the TPS warps show that the principal components do not reflect simple changes in one direction but instead 
Table 11

Classification results between Alkmaar and Middenbeemster, based on 10,000 permutations.

\begin{tabular}{|c|c|c|c|c|}
\hline Cross-validated classification results in \% & MB female & PAA female & MB male & PAA male \\
\hline MB female & 56.5 & 17.4 & 17.4 & 08.7 \\
\hline PAA female & 13.0 & 65.2 & 04.4 & 17.4 \\
\hline MB male & 17.9 & 07.1 & 53.6 & 21.4 \\
\hline PAA male & 00.0 & 21.4 & 35.7 & 42.9 \\
\hline
\end{tabular}

$\mathrm{MB}=$ Middenbeemster, $\mathrm{PAA}=$ Alkmaar

represent changes in shape in multiple locations on the mandible. Thus, their variation was hard to interpret. A similar study investigated the variation in a sample of 155 modern human mandibles with 28 fixed landmarks. After having performed a PCA, it was found that the first 25 PC's accounted for $91.4 \%$ of the total variation (Nicholson and Harvati, 2006). This confirms that the mandible is a complex three-dimensional structure, and many shape variables are required to capture the variation in its morphology. In order to deal with this, all of the statistical analyses that were performed after the PCA have included all of the shape variables, in order to prevent loss of significant data.

Tables 11 and 12 detail the cross-validated classification of the sexes and the archaeological sites. These tables elucidate the results explained in the previous section. Table 11 shows the low percentage of correct classification (highest is 56.5\% for the Middenbeemster females; Table 11). Table 12 shows that, when separating the sites, Alkmaar has a higher percentage of correct classification when compared to Middenbeemster (Table 12). This is possibly caused by a small number of males, as well as a lower degree of correlation between vectors of shape change in the individuals from Alkmaar, instead of it being an evidence of a greater sexual dimorphism in Alkmaar per se. Moreover, the classification results also point out that the correct estimation of sex, using these shape variables is quite low (average of 75\%). Therefore, one should be careful when estimating the sex of individuals in these and possibly other populations, as the hypothesis that the estimation of sex based on mandibles in the Low Countries is not accurate seems to be valid.

The low accuracy associated with the classification of the correct sex and sample combination (55.7\%) is probably produced by the fact that the criterion "site" was not based on direct observation of a variable but rather on an a priori classifier used to give some indication of the temporal and spatial components of the sample distribution. While cross-validation cannot be used as statistically valid evidence, it does show that there is a large amount of overlap between the mandibles from both sexes and two archaeological sites. If the modern sample is included in the cross-validated classification, the correct classification becomes even lower (45.1\%), which highlights the fact that we should not rely on statistical cross-validation based on the shape variables used in this study in order to determine the sex of an individual.

The ANOVA on the centroid sizes showed that Alkmaar males possessed the largest mandibles by far, followed by the males from ArtiVarK and Middenbeemster. The females from ArtiVarK and Alkmaar have comparable mandible sizes and Middenbeemster females had the smallest mandibles on average. The most important cause of the size differences between males and females is likely due to the sexual dimorphism of growth (Godde, 2015). The Procrustes ANOVAs show that there was significant difference in shape between the sexes and between the archaeological sites. Subsequent analyses show that when the influence of size is not accounted for, there are differences in the amount or magnitude of shape change between the two sexes in Middenbeemster. The results also suggest that the male mandibles show a different kind of shape change compared to female mandibles, when it comes to the corpus.

Table 12

Cross-validated results on the between group PCA between the two sexes, for Alkmaar and Middenbeemster, based on 10,000 permutations.

\begin{tabular}{llc}
\hline Classification results & Female & Male \\
\hline Female & 78.3 & 21.7 \\
Male & 28.6 & 71.4 \\
\hline Classification results & Female & Male \\
Middenbeemster & & \\
\hline Female & 69.6 & 30.4 \\
Male & 32.1 & 67.9 \\
\hline & & Male \\
Classification results & Female & \\
Alkmaar & & 21.7 \\
\hline Female & 78.3 & 78.6 \\
Male & 21.4 & \\
\hline
\end{tabular}


Thus, as size increases, the shapes of the mandibles of males and females are deformed in somewhat different directions in tangent space (Tables 5 and 6). The male and female individuals from Alkmaar only show a significant heterogeneity of slopes when analyzing the total configuration and the rami separately. This suggests that the male individuals from Alkmaar exhibit a different kind of shape change in the ramus compared to the female individuals from the same site. When size is accounted for as a factor, these differences disappear.

Concerning differences in magnitude of sexual dimorphism between the sites, the results show that Middenbeemster males and females differ in the amount of size-shape change, while the Alkmaar males and females do not. This would suggest that the magnitude of sexual dimorphism is lower in Alkmaar than Middenbeemster, at least in size-shape space. Another interesting trend is the lack of significant shape differences between the male individuals from Middenbeemster and the female individuals from Alkmaar. Likewise, there are also no significant shape differences between the female individuals from Middenbeemster and the male individuals from Alkmaar. This would suggest that there is no significant sexual dimorphism when the two sites are compared. In Middenbeemster, the corpus is the focal point of the sexual dimorphism: females from Middenbeemster possess rami that assume a more masculine pattern on average. Likewise, males from Alkmaar have a mandibular corpus that is more or less comparable to the female mandibular corpus of Middenbeemster. Therefore, one reason why these groups do not show significant differences when compared to each other could be that the area of the expression of sexual dimorphism has shifted between the two sites.

Furthermore, there do not seem to be significant differences in size-shape space with the ArtiVarK sample included in the analyses, except between the males and females from Middenbeemster. While this could have been the result of an actual reduction in sexual dimorphism in the modern period, it is more likely that the landmarks presented here did not represent the areas with the most sexual dimorphism effectively, due to their wide spacing and thus low amount of surface coverage. Sexual dimorphism is likely more finely grained between these three periods. The persistence of an effect between the males and females from Middenbeemster could be the result of the earlier mentioned magnitude of sexual dimorphism in the mandibles from Middenbeemster. However, it also needs to be considered that Alkmaar and ArtiVarK have smaller sample sizes, which might contribute to a lack of variation.

The discrepancy in size between individuals from the samples is not only influenced by sexual dimorphism but also by other factors such as diet, climate and geographic patterning (Bejdová et al., 2013; Hubbe et al., 2009; Nicholson and Harvati, 2006). As outlined in the introduction, there are reasons to expect that the diet of Middenbeemster (post-Medieval period) was softer than that of Alkmaar, and that food was more highly processed. This is likely reflected in the smaller Middenbeemster mandibles.

The reduction in size of the mandible does not continue into the modern period, at least not within the ArtiVarK sample. The male mandibles from ArtiVarK are non-distinguishable in terms of size when compared with the male mandibles from Alkmaar and Middenbeemster. Only the females from ArtiVarK and Alkmaar display a significant difference in size. If one would follow the reasoning outlined above, it would be expected that the female mandibles from the modern period would be the smallest on average, since our modern food should be the softest (Mew, 2014). However, other factors may have an influence on mandibular size, such as the marked positive secular trend of height in the Netherlands in the last 150 years (Stulp et al., 2015). The taller average stature of the modern period $(1753 \mathrm{~mm}$ ) compared to the estimated mean statures (1672 mm and $1666 \mathrm{~mm}$ for Alkmaar and Middenbeemster respectively) could have counteracted the effect of diet, as stature does have correlation with mandibular size in this sample. This is further confirmed by significant differences found in stature between the archaeological sites and the modern sample. Thus, the differences between the females from ArtiVarK and Alkmaar could simply be an effect of the taller stature of the Alkmaar females. However, one does need to keep in mind that the stature in the modern sample was measured on the participants directly, while the stature for the archaeological samples was estimated from long bones following the method of Trotter (1970). This method is far from perfect, as Petersen (2005) has pointed out. He has reported that in his sample, which was obtained from a Medieval Danish cemetery, the method devised by Trotter and Gleser tended to overestimate stature by $41.5 \mathrm{~mm}$. In the end, one needs to keep in mind that we are comparing a directly observed measurement of length during life with an estimation of stature during life based on dry bones.

Coming back to the differences between the sexes, the difference between the rami is especially interesting. In Middenbeemster, the ramus shows much less lateral displacement between the sexes. This flexure is much more marked in the Alkmaar collection. These differences in ramus flexure are likely the effect of changes in the magnitude of the force produced by the masseter muscle. The reduced lateral flexure in Middenbeemster is likely caused by the intake of an increased amount of soft food (Martin and Danforth, 2009). Thus, it seems reasonable to suggest that the softer diet was an important factor in both the decrease in average size of the mandible and a change in average shape. It is possible that the greater lateral flexure of Alkmaar females compared to the Alkmaar males could have been caused, in part at least, by a dietary difference.

While life history theory, as outlined in the introduction, provides a possible connection between sexual dimorphism and diet, linking this hypothesis to the results presented here is not easily done. In Alkmaar, both the wealthy and poor citizens were buried in the monastery, while in Middenbeemster, mainly common citizens from the surrounding villages were buried in the communal graveyard (Griffioen et al., 2015; Lemmers et al., 2013). This could suggest, on very tentative grounds, that the mandibles from Middenbeemster were smaller on average because of poorer living conditions. However, both of the archaeological samples express numerous stress indicators such as enamel hypoplasia and Harris lines, suggesting sub-optimal conditions for both samples, although a formal study on the differences in prevalence has not yet been performed. Also, the exact composition of wealthy versus poor individuals is not known for the populations in general, nor for the sample used in this research.

Furthermore, while it can be argued that malnutrition stunts early growth, the exact nature of the relationship between energy availability, malnutrition and the size of the mandible is not well-understood.

In a comparative study of stature variation between archaeological samples and living people, Vercellotti et al. (2014) found that modern populations generally enjoyed less physiological stress than individuals from the Medieval period. Therefore, the individuals from the ArtiVarK study are suspected to be of better health and nutrition due to current living standards in the Netherlands, as well as their 
significantly taller stature. However, as Vercellotti et al. (2014) rightfully point out, stature might not be the best indication for health per se. Nonetheless, there is no specific information available on general and specific stress markers (influence of possible diseases/impairments) for the individuals from the ArtiVarK sample. Thus, it is hard to substantiate with direct data at this moment in time.

Another large point of contention is the fact that some of the similarities in mandibular morphology between the samples, especially when including the recent ArtiVarK sample, might be the result of shared population history. While some scholars argue that the mandible is of not much value in identifying recent human populations (e.g. Humphrey et al., 1999), other recent studies have pointed out that actually, the mandible can reflect population history quite well, as inferred from geographical distance between populations (Nicholson and Harvati, 2006; Harvati and Weaver, 2006), but also from "population continuity" (Galland et al., 2016; Šešelj et al., 2015). Geographical distance might be a fairly robust proxy for inferring restricted gene flow between populations and a good estimate of different climatic conditions. Given the fact that the sites of Alkmaar and Middenbeemster are not separated by a great geographical distance ( $14.8 \mathrm{~km}$ as the crow flies), it is fair to assume that there was some genetic continuity between these two temporally divided populations. It may very well be the case that some of the individuals from Middenbeemster were direct descendants of the population of Alkmaar. On top of that, participants from the ArtiVarK study might share a fairly recent genetic affinity either with one or both the archaeological samples. One way to check the genetic similarity when populations are not separated by large geographical distances is to extract and compare nuclear DNA. However, it is far beyond the scope of the current paper to include any kind of genetic data.

To return to the actual results, this study represents the first time that geometric morphometrics has been applied to archaeological skeletal samples in the Netherlands and sheds light on variation in the shape and size of human mandibles from the archaeological sites of Alkmaar (1484-1574 CE) and Middenbeemster (1829-1866 CE), and the participants from the ArtiVarK study, through the use of landmark-based geometric morphometrics. The results illustrate the difficulty of distinguishing shape variation between these three samples. There is a large overlap between the ranges for individuals from different groups, and the variation within the groups is extremely large compared to the variation between groups. However, our statistical analysis indicates that there is a slight shift in mean shape associated with size and expression of shape variation between the sites of Alkmaar and Middenbeemster. Concerning this variation, our research has pointed out that the expression of sexual dimorphism has changed over time when comparing these three sites and that dietary differences very possibly had an effect on mandibular size. Coming back to the overarching project, in future research, we plan to incorporate a PCA model based on the entire set of 3D mandible scans into ArtiSynth (Lloyd et al., 2012) to examine the effect of this variation on speech biomechanics.

To conclude, this research has attested that the shape and size of the mandible are sensitive to changes over very short periods of time and supports previous work, which has shown that diet and food processing are primarily responsible for a large amount of anatomical variability. While this study has significance for much of the late Medieval and early Industrial periods in the Netherlands, there are broader implications as well. On a national level, it has provided more evidence for the unreliability of the mandible as a source for the determination of sex in Dutch skeletal material. The mandible is not a set structure which form is mainly determined by stature and sex, but rather an adaptive mechanism that responds quickly to new or changing stress factors. This is not only true for human skeletal remains from the Netherlands but also for both past and current populations all over the world. Thus, during the recovery, identification and analysis of human bone material, we should be very aware of this plasticity. A thorough investigation of diet and types of processing in a specific population is needed to fully comprehend the variability seen in the skeletal material. However, this should not supersede the exploration of other factors that might have influence on the mandible, such as dental health, stature, shape of the cranium, climate, and population history. Moreover, the exploration of alternative hypotheses should be encouraged, as this can only increase our knowledge of our own biology. Ultimately, any investigation into structures of the human skeleton should not only rely on qualitative data or linear metrics but also on other methods that have the power to either supplement or shed new light on traditional methods and ideas.

\section{Acknowledgements}

We wish to thank David Norris, Paul Gaalman, Frans Delfos, Cees Kreulen, Thomas Maal and Sabine Kooijman for making ArtiVarK possible; Carly Jaques for recruiting and managing our participants; the participants in the ArtiVarK project for their time and patience. AB was supported by the German Research Foundation (DFG FOR 2237: Project "Words, Bones, Genes, Tools: Tracking Linguistic, Cultural and Biological Trajectories of the Human Past"). DD and SRM were supported by the Netherlands Organization for Scientific Research (NWO) VIDI grant 276-70-022.

The osteological collections of Alkmaar and Middenbeemster are situated in the Laboratory for Osteoarchaeology in the Leiden University under the direction of A.W. The data from the ArtiVarK study are currently being researched at the Max Planck Institute for Psycholinguistics in Nijmegen.

We appreciate the helpful and insightful comments of the editorial board, Dr. Kanya Godde, and one anonymous reviewer, which have greatly improved this paper.

\section{References}

Adams, D.C., Otarola-Castillo, E., 2013. Geomorph: an R package for the collection and analysis of geometric morphometric shape data. Methods Ecol. Evol. 4, 393-399. Alarcón, J.A., Bastir, M., Rosas, A., 2016. Variation of mandibular sexual dimorphism across human facial patterns. HOMO - J. Comp. Hum. Biol. 67, $188-202$.

Bejdová, Š., Krajíček, V., Velemínská, J., Horák, M., Velemínský, P., 2013. Changes in the sexual dimorphism of the human mandible during the last 1200 years in Central Europe. HOMO - J. Comp. Hum. Biol. 64, 437-453.

Bookstein, F.L., 1991. Morphometric Tools for Landmark Data: Geometry and Biology. Cambridge University Press, Cambridge. 
Brooks, S., Suchey, J.M., 1990. Skeletal age determination based on the os pubis: a comparison of the Acsádi-Nemeskéri and Suchey-Brooks methods. Hum. Evol. 5, 227-238. Brunner, J., Fuchs, S., Perrier, P., 2009. On the relationship between palate shape and articulatory behavior. J. Acoust. Soc. Am. 125, 3936-3949.

Buckberry, J.L., Chamberlain, A.T., 2002. Age estimation from the auricular surface of the ilium: a revised method. Am. J. Phys. Anthropol. 119, 231-239.

Buikstra, J.E., Ubelaker, D.H., 1994. Standards for Data Collection from Human Skeletal Remains. Arkansas Archaeological Survey, Fayetteville, Arkansas.

Collyer, M.L., Sekora, D.J., Adams, D.C., 2015. A method for analysis of phenotypic change for phenotypes described by high-dimensional data. Heredity 115, 357-365.

Dediu, D., 2011. Are languages really independent from genes? If not, what would a genetic bias affecting language diversity look like? Hum. Biol. 83, 279-296.

Dediu, D., Ladd, D.R., 2007. Linguistic tone is related to the population frequency of the adaptive haplogroups of two brain size genes, ASPM and Microcephalin. Proc. Natl. Acad. Sci. U. S. A. 104, 10944-10949.

Dediu, D., Janssen, R., Moisik, S.R., 2017. Language is not isolated from its wider environment: vocal tract influences on the evolution of speech and language. Lang. Commun. 54, 9-20.

Dediu, D., Moisik, S., 2016. Anatomical biasing of click learning and production: an MRI and 3D palate imaging study. In: Roberts, S.G., Cuskley, C., McCrohon, L., BarcelóCoblijn, L., Fehér, O., Verhoef, T. (Eds.), The Evolution of Language: Proceedings of the 11th International Conference (EVOLANGX11), . http://evolang.org/neworleans/ papers/57.html.

Franklin, D., O’Higgins, P., Oxnard, C., Dadour, I., 2007. Sexual dimorphism and population variation in the adult mandible. Forensic Sci. Med. Pathol. 3, 15-22.

Godde, K., 2015. Secular trends in cranial morphological traits: a socioeconomic perspective of change and sexual dimorphism in North Americans 1849-1960. Ann. Hum. Biol. $42,253-259$.

Griffioen, A.A.J., Hakvoort, S., Schats, R., Bitter, P., Beerenhout, B., Brinkhuizen, D.C., Alkmaar, G., van Daalen, S., Hermsen, R., 2015. Graven en begraven bij de Minderbroeders: een archeologische opgraving op de Paardenmarkt in Alkmaar. Monumentenzorg en Archeologie van de Gemeente Alkmaar, Alkmaar.

Hill, K., Kaplan, H., 1999. Life history traits in humans: theory and empirical studies. Annu. Rev. Anthropol. 28, 397-430.

Hu, K.-S., Koh, K.-S., Han, S.-H., Shin, K.-J., Kim, H.-J., 2006. Sex determination using nonmetric characteristics of the mandible in Koreans. J. Forensic Sci. 51, $1376-1382$. Hubbe, M., Hanihara, T., Harvati, K., 2009. Climate signatures in the morphological differentiation of worldwide modern human populations. Anat. Rec. 292 , $1720-1733$.

Humphrey, L.T., Dean, M.C., Stringer, C.B., 1999. Morphological variation in great ape and modern human mandibles. J. Anat. 195, 491-513.

İşcan, M.Y., Loth, S.R., Wright, R.K., 1984. Metamorphosis at the sternal rib end: a new method to estimate age at death in white males. Am. J. Phys. Anthropol. 65, 147-156. Kemkes-Grottenthaler, A., Löbig, F., Stock, F., 2002. Mandibular ramus flexure and gonial eversion as morphologic indicators of sex. HOMO - J. Comp. Hum. Biol. 53, 97-111. Lemmers, S., Schats, R., Hoogland, M., Waters-Rist, A., 2013. Fysisch antropologische analyse Middenbeemster. In: Hakvoort, A. (Ed.), De begravingen bij de Keyserkerk te Middenbeemster. Hollandia reeks 464. Hollandia Archeologen, Zaandijk, pp. 35-60.

Lieberman, D.E., Krovitz, G.E., Yates, F.W., Devlin, M., St Claire, M., 2004. Effects of food processing on masticatory strain and craniofacial growth in a retrognathic face. J. Hum. Evol. 46, 655-677.

Little, B.B., Buschang, P.H., Peña Reyes, M.E., Tan, S.K., Malina, R.M., 2006. Craniofacial dimensions in children in rural Oaxaca, Southern Mexico: secular change, 1968-2000. Am. J. Phys. Anthropol. 131, 127-136.

Lloyd, J.E., Stavness, I., Fels, S., 2012. ArtiSynth: a fast interactive biomechanical modeling toolkit combining multibody and finite element simulation. In: Payan, Y. (Ed.), Soft Tissue Biomechanical Modeling for Computer Assisted Surgery. Springer, Berlin, Heidelberg, pp. 355-394.

Loth, S.R., Henneberg, M., 1996. Mandibular ramus flexure: a new morphologic indicator of sexual dimorphism in the human skeleton. Am. J. Phys. Anthropol. 99, 473-485.

Loth, S.R., Henneberg, M., 2000. Gonial eversion: facial architecture, not sex. HOMO - J. Comp. Hum. Biol. 51, 81-89.

Maat, G.J., 2001. Diet and age-at-death determinations from molar attrition. A review related to the Low Countries. J. Forensic Odonto-Stomatol. 19, 18-21.

Maat, G.J.R., Mastwijk, R.W., Van der Velde, E.A., 1997. On the reliability of non-metrical morphological sex determination of the skull compared with that of the pelvis in the Low Countries. Int. J. Osteoarchaeol. 7, 575-580.

Magner, J.A., Rogol, A.D., Gorden, P., 1984. Reversible growth hormone deficiency and delayed puberty triggered by a stressful experience in a young adult. Am. J. Med. 76 , 737-742.

Martin, D.C., Danforth, M.E., 2009. An analysis of secular change in the human mandible over the last century. Am. J. Hum. Biol. 21, 704-706.

Mathworks Inc, 2016. Matlab R2016a. Mathworks Inc., Natick, MA.

Meindl, R.S., Lovejoy, C.O., 1985. Ectocranial suture closure: a revised method for the determination of skeletal age at death based on the lateral-anterior sutures. Am. J. Phys. Anthropol. 68, 57-66.

Mew, M., 2014. Craniofacial dystrophy. A possible syndrome? Br. Dent. J. 216, 555-558.

Mitteroecker, P., Gunz, P., Bernhard, M., Schaefer, K., Bookstein, F.L., 2004. Comparison of cranial ontogenetic trajectories among great apes and humans. J. Hum. Evol. 46, 679-698.

Moisik, S., Dediu, D., 2015. Anatomical biasing and clicks: preliminary biomechanical modelling. In: Hannah, L. (Ed.), The Evolution of Phonetic Capabilities: Causes Constraints, Consequences. ICPhs, Glasgow, pp. 8-13.

Moisik, S.R., Dediu, D., 2017. Anatomical biasing and clicks: evidence from biomechanical modeling. J. Lang. Evol. 2, 37-51.

Nicholson, E., Harvati, K., 2006. Quantitative analysis of human mandibular shape using three-dimensional geometric morphometrics. Am. J. Phys. Anthropol. 131, 368-383.

Oettlé, A., Pretorius, E., Steyn, M., 2009. Geometric morphometric analysis of the use of mandibular gonial eversion in sex determination. HOMO - J. Comp. Hum. Biol. 60, $29-43$.

Paschetta, C., de Azevedo, S., Castillo, L., Martinez-Abadias, N., Hernandez, M., Lieberman, D.E., Gonzalez-Jose, R., 2010. The influence of masticatory loading on craniofacial morphology: a test case across technological transitions in the Ohio valley. Am. J. Phys. Anthropol. 141, $297-314$.

Petersen, H.C., 2005. On the accuracy of estimating living stature from skeletal length in the grave and by linear regression. Int. J. Osteoarchaeol. 15, 106-114.

Perez, S., Bernal, V., Gonzalez, P.N., 2006. Differences between sliding semilandmark methods in geometric morphometrics, with an application to human craniofacial and dental variation. J. Anat. 208, 769-784.

Phenice, T.W., 1969. A newly developed visual method of sexing the os pubis. Am. J. Phys. Anthropol. 30, $297-301$.

Quintelier, K., Ervynck, A., Müldner, G., Van Neer, W., Richards, M.P., Fuller, B.T., 2014. Isotopic examination of links between diet, social differentiation, and DISH at the postmedieval Carmelite Friary of Aalst, Belgium. Am. J. Phys. Anthropol. 153, 203-213.

Rando, C., Hillson, S., Antoine, D., 2014. Changes in mandibular dimensions during the mediaeval to post-mediaeval transition in London: a possible response to decreased masticatory load. Arch. Oral Biol. 59, 73-81.

Reitsema, L.J., Vercellotti, G., 2012. Stable isotope evidence for sex- and status-based variations in diet and life history at medieval Trino Vercellese, Italy. Am. J. Phys. Anthropol. $148,589-600$.

Schmittbuhl, M., Le Minor, J.M., Taroni, F., Mangin, P., 2001. Sexual dimorphism of the human mandible: demonstration by elliptical Fourier analysis. Int. J. Legal Med. 115, $100-101$.

Seeman, E., 2001. Sexual dimorphism in skeletal size, density, and strength. J. Clin. Endocr. Metab. 86, 4576-4584.

Šešelj, M., Duren, D.L., Sherwood, R.J., 2015. Heritability of the human craniofacial complex. Anat. Rec. 298, 1535-1547.

Singman, J.L., 1999. Daily Life in Medieval Europe. Greenwood Press, Westport, CN.

Steyn, M., İşcan, M.Y., 1998. Sexual dimorphism in the crania and mandibles of South African whites. Forensic Sci. Int. 98, 9-16.

Stulp, G., Barrett, L., Tropf, F.C., Mills, M., 2015. Does natural selection favour taller stature among the tallest people on earth? Proc. Natl. Acad. Sci. U. S. A. 282, 1-9. http://dx. doi.org/10.1098/rspb.2015.0211.

Thayer, Z.M., Dobson, S.D., 2010. Sexual dimorphism in chin shape: implications for adaptive hypotheses. Am. J. Phys. Anthropol. 143, $417-425$.

Tiede, M.K., Gracco, V.L., Shiller, D.M., Espy-Wilson, C., Boyce, S.E., 2005. Perturbed palatal shape and North American English/r/production. J. Acoust. Soc. Am. 117, $2568-2569$.

Trotter, M., 1970. Estimation of stature from intact long bones. In: Steward, T. (Ed.), Personal Identification in Mass Disasters. Smithsonian Institution Press, Washington, D.C, pp. 71-83.

Tuli, A., Choudhry, R., Choudhry, S., Raheja, S., Agarwal, S., 2000. Variation in shape of the lingula in the adult human mandible. J. Anat. 197, 313-317.

Vanhaute, E., O'Gráda, C., Paping, R., 2007. The European subsistence crisis of 1845-1850. A comparative perspective. In: Paping, R., Vanhaute, E., Ó Gráda, C. (Eds.), When the Potato Failed: Causes and Effects of the Last European Subsistence Crisis, 1845-1850. Comparative Rural History of the North Sea Area. CORN Publication Series 9. Brepols, Turnhout, pp. 15-40.

Vercellotti, G., Piperata, B.A., Agnew, A.M., Wilson, W.M., Dufour, D.L., Reina, J.C., Boana, R., Justus, H.M., Larsen, C.S., Stout, S.D., Sciulli, P.W., 2014. Exploring the multidimensionality of stature variation in the past through comparisons of archaeological and living populations. Am. J. Phys. Anthropol. 155, 229-242.

von Cramon-Taubadel, N., 2011. Global human mandibular variation reflects differences in agricultural and hunter-gatherer subsistence strategies. Proc. Natl. Acad. Sci. U. S. A. 
108, 19546-19551.

Weisensee, K.E., Jantz, R.L., 2011. Secular changes in craniofacial morphology of the Portuguese using geometric morphometrics. Am. J. Phys. Anthropol. 145, 548-559.

Wickham, H., 2009. ggplot2: Elegant Graphics for Data Analysis. Springer-Verlag, New York.

Wiel, v.d.K., 2012. Piepers, blauwschokkers en augurken: Akkerbouwers en tuinder. In: Aten, D., Bossaers, K., Dehé, J., Kurpershoek, E., Misset, C., Schaap, E., Steenhuis, M., van der Wiel, K. (Eds.), 400 Jaar Beemster 1612-2012. Stichting Uitgerverij Noord-Holland, Wormerveer.

Wiley, D.F., Amenta, N., Alcantara, D.A., Ghosh, D., Kil, Y.J., Delson, E., Harcourt-Smith, W., Rohlf, F.J., St John, K., Hamann, B., 2005. Evolutionary morphing. Proceedings of the Visualization, 2005. VIS 05. IEEE, pp. 431-438.

Zelditch, M.L., Swiderski, D.L., Sheets, H.D., 2012. Geometric Morphometrics for Biologists, 2nd ed. Academic Press, San Diego.

Zink, K.D., Lieberman, D.E., 2016. Impact of meat and Lower Palaeolithic food processing techniques on chewing in humans. Nature 531, 500-503. 